\title{
SOSIALISASI PENGENALAN INVESTASI PASAR UANG \& MODAL DIKALANGAN GENERASI Z (KHUSUS MAHASISWA DAN UMUM) DI PEKANBARU
}

\author{
Christ Windreis ${ }^{1^{*}}$ \\ Wira Jaya Hartono ${ }^{2}$ \\ Yanti $^{3}$ \\ 1,2,3 STMIK Dharmapala Riau, Pekanbaru, Indonesia \\ christ.windreis@lecturer.stmikdharmapalariau.ac.id ${ }^{*}{ }^{*}$ \\ Wira.jh@lecturer.stmikdharmapalariau.ac.id $\left.{ }^{2}\right)$ \\ yantijiang.4721@gmail.com ${ }^{3)}$
}

\author{
Kata Kunci: \\ [Sosialisasi; \\ Investasi; Forex; \\ Pasar Saham; \\ Generasi X]
}

\begin{abstract}
Abstrak: Dengan Perkembangan teknologi yang begitu cepat sangat memperngaruhi masyarakat diseluruh dunia menjadi sensitif pada semua informasi termasuk pasar saham dan uang. Di Indonesia, jumlah ketertarikan pada dunia saham dan pasar uang sangat meningkat dengan signifikan untuk menjadi investor, tanpa mereka ketahui dengan benar. Dengan kecepatan informasi dimedia sosial, masyarakat langsung bergabung tanpa mempelajari atau diedukasi tentang resiko yang dihadapi. Ketika pasar tidak begitu baik. Ada beberapa hasil yang tidak bisa terima dan mereka tidak mengetahui cara mengatur atau menghadapi resiko tersebut. Sehingga hasilnya, banyak uang diinvestasikan menjadi berkurang bahkan hilang. Dengan adanya kejadian seperti ini, sosialisasi ini berfokus pada generasi $\mathrm{Z}$ yang ada di kota Pekanbaru. Kegiatan ini memaparkan bagaimana pengenalan pada pasar saham dan uang dan bagaimana cara mengatur resiko. Metode dalam sosialisasi ini menggunakan daring atau zoom meeting yang dikuti oleh 27 peserta. Dari hasil kusioner masih terdapat $74 \%$ belum mengetahui atau bergabung dalam investasi saham atau forex. Dari analisis t-test terdapat perbedaan hasil pemahaman antara pre test dan postest. Dan juga minat berinvestasi dipasar saham masih tinggi secara keinginan sendiri, dikuti oleh adanya iklan dan influencer saham yang memperngaruhi orang-orang untuk menjadi investor, lalu ajakan atau ikut-ikutan teman. Sehingga seluruh peserta juga menginginkan pelatihan atau workshop secara mendalam mengenai pasar uang dan saham.
\end{abstract}

Published by:

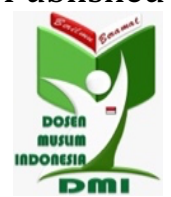

Copyright (C) 2021 The Author(s)

This article is licensed under CC BY 4.0 License

(cc) $\mathrm{BY}$

https://dmi-journals.org/jai/ 


\section{Pendahuluan}

Pada awal tahun 2020 hingga sekarang ini publik dikejutkan oleh maraknya iklaniklan investasi pasar modal di media sosial baik itu facebook, Tik Tok, Instagram, youtube dan laman-laman browsing. Dengan besarnya marketing investasi pasar modal di media internet ditambah penggunaan internet di Indoensia yang sangat masif, tidak sedikit para pengguna internet tergiur oleh iming-iming dengan keuntangan yang besar. Padahal mereka tidak mengenal cara dan resiko yang akan dihadapi oleh mereka terutama pada kaum milenial. Ada beberapa alasan kenapa sosialisasi ini ditargetkan kepada kaum melenial.

Pertama, di Indonesia sendiri, pasar modal sendiri merupakan investasi yang sangat populer oleh masyarakatnya. Dari data OJK tahun 2020, Dominasi Milenial di Pasar Modal Selain itu, investor di pasar modal kini juga didominasi oleh generasi milenial. Rinciannya, total investor berusia di bawah 30 tahun hampir 45\% dari total investor pasar modal. Sedangkan untuk investor dengan rentan usia 31 tahun hingga 40 tahun sebesar $25 \%$ dari total ivenstor di pasar modal. Dalam empat tahun terakhir memang investor milenial terus mengalami peningakatan. Bahkan untuk usia antara 18 hingga 25 tahun jumlahnya meningkat 338\% sejak 2016 yang lalu. Berdasarkan CNBC indonesia pada tahun ini 2021 Investor Pasar Modal RI didominasi Milenial Tembus 3,34 Juta

Kedua, ditambah lagi mudahnya melakukan peminjaman online (pinjol) membuat generasi melakukan pinjaman dengan mudah. Berdasarkan keterangan resmi OJK, yang dikutip dari Republika pengguna fintech lending meningkat seiring jumlah peminjam atau borrower maupun pemberi pinjaman atau lender di tengah pandemi. Akumulasi rekening borrower tumbuh 136,33 persen menjadi 40,75 juta entitas, sebanyak 67,35 persen merupakan kaum milenial.

Dan juga rupanya hal ini dimanfaatkan oleh generasi melenial untuk melakukan investasi di pasar modal. Namun investasi tidak sejalan dengan yang diperkiraan sehingga equitas menurun dratis. Disamping itu, mereka juga harus menjalankan kewajiban membayar hutang di pinjaman online. Alhasil mereka tidak bisa melunasi sehingga terperangkap disituasi yang buntu. Jalan keluarnya adalah melakukan tindakan kriminal seperti merampok, mencuri, menipu dan lain lain.

Ketiga, menurut Sri Utami (2015) dibutuhkannya manajemen psikologi dalam berinvesstasi saham, dan psikologi dan ciri-ciri generasi z, menurut Poluakan (2019) yaitu sangat berorientasi pada teknologi yang sangat peka terhadap teknologi atau gadget, ingin mendapatkan sesuatu dengan cepat, seperti kenaikan karir, kekayaan, dan lain-lain. Hal ini membuat mereka cendrung tidak sabar dalam mengambil keputusan, ditambah lagi dengan informasi yang cepat di sosial media membuat mereka tidak mau menganalisa dan memperdalam pengetahuan dalam mengambil keputusan. Didukung oleh Hartono (2021) mengenai pendidikan secara online harus dilaksanakan dengar benar dan tetap sesuai sasaran. Yang ada dalam pikiran mereka adalah mendapatkan harapan sesegera mungkin tanpa memperhatikan proses. Alhasil terjadilah hal-hal seperti berinvestasi dengan uang panas, meminjam dari fintech lending atau applikasi pinjaman online, uang arisan, uang nikah, menggadaikan surat tanah dan lain-lain. Disatu sisi pandangan generasi $\mathrm{z}$ hanya melihat keuntungan yang sering dipamerkan di social media oleh pada influencer saham, sehingga melihat berinvestasi merupakan jalan tercepat untuk mendapatkan kekayaan. Hal ini membuat mereka lupa akan risiko dibalik berinvestasi. 
Untuk menghindari hal tersebut maka pentingnya untuk mengetahui terlebih dahulu apa itu investasi dipasar modal dan uang serta bagaimana cara kerjanya sebelum memutuskan untuk turut turun main dalam dunia investasi agar dapat meminimalisir resiko

\section{Metode Pelaksanaan}

Pelaksanaan kegiatan Pelatihan Bahasa Inggris untuk membangun manajemen pelayanan prima pada staff Taman Baca Kesiman Bali dilaksanakan secara bertahap sehingga mampu menghasilkan pelatihan yang mampu memiliki luaran dan capaian sesuai dengan yang di inginkan. Adapun tahap-tahap dalam pelaksanaan kegiatan ini adalah sebagai berikut;

Pelaksanaan kegiatan ini meliputi persiapan, pelaksanaan, pelaporan, hingga tindak lanjutnya. Metode yang dilaksanakan sebagai berikut:

1. Kegiatan ini dilaksanakan dengan membuat flyer untuk mengundang para partisipan untuk bergabung didalam zoom meeting.

2. Peserta didik akan melakukan registrasi secara online dan disertakan pre test di dalamnya.

3. Kegiatan sosialisasi berlangsung pada 10 April 2021, setelah selesai kegiatan, peserta akan mengikuti post test.

4. Metode analisis adalah metode stastik yaitu analisis deskriptif dengan t-test. Hipotesis yang digunakan yakni:

$\mathrm{H}_{0}$ : Terdapat perbedaan yang signifikan antar hasil sosialisasi pada data pretest dan posttest.

$\mathrm{H}_{1}$ : Tidak terdapat perbedaan yang signifikan antar hasil sosialisasi pada data pretest dan posttest.

\section{Hasil dan Pembahasan}

Ada pun materi yang yang disampaikan yaitu dimulai dari pasar uang atau forex, ada beberapa survey telah dilakukan rivero (2020) dalam situs daily forex menyebutkan beberapa jawaban dari 3127 trader dan investor dari 32 negera didalam pasa uang diantaranya yaitu oleh Berapa banyak trader yang sukses dan berapa tingkat kesuksesan trader Forex? Serta benarkah 90\% trader kehilangan uang? Kami telah menanyakan para peserta apakah secara keseluruhan mereka kalah atau memenangkan uang. Menurut survei kami 85\% pedagang eceran Forex tidak berhasil.

Jadi mengapa kebanyakan trader gagal? 85\% dari mereka yang berdagang selama lebih dari 4 tahun mengklaim menang. Untuk menjadi trader yang sukses, Anda membutuhkan pemahaman yang baik tentang pasar. Hanya dengan demikian Anda dapat mengembangkan strategi dan disiplin perdagangan. Pedagang profesional sering mengatakan bahwa mereka kehilangan banyak uang di awal perjalanan perdagangan mereka karena mereka tidak memiliki pengetahuan, strategi, atau disiplin untuk sukses. Mayoritas pedagang yang menguntungkan menghabiskan setidaknya 4 tahun kehilangan uang sebelum mereka dapat membangun rencana perdagangan yang menang. Jika Anda tidak memiliki latar belakang profesional di pasar keuangan, ini bisa menjadi lebih sulit. 
Berapa persentase dari keseluruhan anggaran anda yang anda belanjakan untuk trading forex? Mayoritas trader yang kami survei berisiko kurang dari 5\% dari keseluruhan anggaran mereka untuk trading forex.

Sedangkan dalam pasar saham ada beberapa pengetahuan yang perlu diketahui oleh investor awal. Diantaranya yaitu Keuntungan perusahaan go public yaitu Mendapat modal Segar / fresh money untuk ekspansi atau intensifikasi pertumbuhan perusahaan Memberikan nilai tambah bagi perusahaan, dikarenkan laporan keuangan yang dapat di akses oleh masyarakat umum, pihak perbankan sebagai kreditor serta pemerintah sebagai regulator pasar modal dan perekonomian negara Citra perusahaan akan meningkat karena transparency, Untuk keberlangsungan hidup perusahaan (sustainability). Dimana perusahaan melibatkan seluruh pemegang saham baik koporasi maupun retailer (masyarakat umum) mendukung dan mengawasi kinerja untuk keberlangsungan perusahaan.

Pengertian lot, dalam satuan resmi yang ditetapkan oleh bursa efek Indonesia, 1 Lot $=100$ lembar saham Jika harga saham PT. ABC = 500 Maka pembelian 1 lot saham PT. $\mathrm{ABC}=100$ lembar $\mathrm{x} 500=$ Rp. 50.000 maka untuk mendapatkan/ membeli 1 Lot saham PT.ABC, investor harus membayar Rp.50.000, - dari rekening RDN (rekening dana nasabah)

Cara Saham memberikan keuntungan yaitu 1) dengan Deviden laba yang di bagikan oleh perusahaan kepada pemegang saham, berdasar jumlah lembar saham yang di milik Pembagian deviden yang biasa nya di lakukan setahuan sekali oleh perusahaan setelah di tutup nya laporan keuangan tahunan dan RUPS Pembagian deviden yang mempunyai tahapan yang telah di atur UU dan BEI. 2) Capital Gain Pertumbuhan dari nilai aset dan modal selisih antara harga beli dan harga jual saham. 3) Likuiditas yang tinggi Dapat di likuiditas kapan pun, di jam operasional pasar modal Dapat dilikuiditas sebagian sesuai kebutuhan

Perbandingan Nabung Saham dengan menabung konvensional. Pada saham, para investor akan mendapatkan Deviden Capital Gain (Pendapatan Modal) dan pada tahun 2021 Pajak deviden individu (retailer) ditiadakan. Sedangkan, menabung konvensional memiliki BI rate 3.5 persen, rata-rata bunga tabungan konvensional 3 sampai 5 persenan ditambah dengan biaya admistrasi bulanan Pajak bunga sebagai PPH (20\%)

Cara menjadi investor saham yaitu 1) Menyiapkan dokumen pribadi seperti E-Ktp, NPWP, rekening tabungan lalu menentukan perusahaan sekuritas dengen mengecek broker di idx. co. i, Pendaftaran menjadi investor yaitu dengan membuka RDN (rekening dana nasabah) dan akan mendapatkan Kartu keanggotaaan KSEI (Kustodian Sentral Efek Indonesia)

Dana investasi yang didalam berinvestasi di pasar modal, sangat di sarankan dengan menggunakan dana dingin/ idle fund dalam tabungan, Sisa dana dari keuntungan atau sebagian laba dari usaha atau Dana tabungan yang disisihkan dari dana operasional kebutuhan pribadi atau usaha.

Pendekatan dalam memilih Saham terdiri dari dua analisis yaitu Fundamental Analysis yaitu Kondisi makro global, Kondisi makro dalam negeri, prospek pertumbuhan industri dan Fundamental perusahaan Technical Analysis yaitu visualisasi terhadap Chart/graphic, visualisasi terhadap price action, bersifat waktu pendek/short term range. 
Kesimpulan yang diberikan yaitu Mengerti dasar dan perhitungan dari perdagangan forex, crypto dan saham, Menggunakan demo account dalam belajar forex, Menggunakan uang dingin untuk investasi saham / crypto Mempelajari analisa teknikal, Mempelajari analisa fundamental, Membuat trading system, lalu Trading live.

Setelah melakukan sososialisasi, didapat jumlah peserta yang mengikuti Sosialisasi ini sebanyak 27 peserta yang hadir dari flyer yang diberikan seminggu sebelum kegiatan dimulai. Dari sosialisasi ini dapat diketahui bahwa rata-rata pengetahuan peserta peserta masih sangat minim diketahui dari kuesioner yang diberikan sebelum sosialisasi dimulai. Dari kuesioner yang diberikan mengenai informasi pribadi, dan pengetahuan awal didapat:

1. Informasi pribadi yang didapat yaitu Rata-rata peserta yang mengikuti sosialisasi ini berumur 23 tahun.

2. Pekerjaan Peserta yang hadir yaitu sekitar $42 \%$ mahasiswa, $38 \%$ para mahasiswa yang sudah bekerja, 8\% wiraswasta dan 12\% karyawan / PNS

3. Ada sekitar $26 \%$ peserta yang pernah mendapatkan atau mengikuti pelatihan investasi, forex, crypto, saham, reksanadana dan melaksanakan investasi di pasar uang serta saham, dan 74\% belum pernah mengikuti

4. Pertanyaan "Bagaimana ada bisa tertarik dalam dunia pasar modal" didapat ikutikutan teman atau diajak teman 11\%, keinginan sendiri 59\% dan lihat iklan atau influencer saham di sosial media (seperti facebook, twitter, instagram, tiktok, youtube, dll) $26 \%$.

5. Pertanyaan "apakah anda ingin mempelajari ilmu investasi lebih mendalam?" $100 \%$ peserta menjawab "Iya"

6. Setelah mengikuti pre-test dan post test didapat tata-rata nilai pre-test 59.25 dan post test 76.66 . Hal ini bisa dilihat setelah melakukan sosialisasi didapat peningkatan $17.4 \%$ dari pre test.

Tabel 1. Hasil Analisis Paired Sample Test

\begin{tabular}{|c|c|c|c|c|c|c|c|c|}
\hline & \multicolumn{5}{|c|}{ Paired Differences } & \multirow[b]{3}{*}{$\mathrm{t}$} & \multirow[b]{3}{*}{ df } & \multirow{3}{*}{$\begin{array}{l}\text { Sig. } \\
(2- \\
\text { tailed })\end{array}$} \\
\hline & \multirow[b]{2}{*}{ Mean } & \multirow{2}{*}{$\begin{array}{c}\text { Std. } \\
\text { Deviation }\end{array}$} & \multirow{2}{*}{$\begin{array}{l}\text { Std. Error } \\
\text { Mean }\end{array}$} & \multicolumn{2}{|c|}{$\begin{array}{c}95 \% \text { Confidence Interval } \\
\text { of the Difference }\end{array}$} & & & \\
\hline & & & & Lower & Upper & & & \\
\hline $\begin{array}{c}\text { Pair } 1 \text { PRE TEST } \\
\text { - POTST } \\
\text { TEST }\end{array}$ & $\begin{array}{r}- \\
1.7407 \\
4 \mathrm{E} 1\end{array}$ & 15.52729 & 2.98823 & -23.54980 & -11.26501 & -5.825 & 26 & .000 \\
\hline
\end{tabular}

Dari hasil analisis menggunakan SPSS diketahui nilai sig. (2-tailed) sebesar 0.000 $<0.05$, maka dapat simpulkan perbedaan yang signifikan antar hasil sosialisasi pada data pretest dan posttest. Hipotesis $\mathrm{H}_{0}$ diterima. 


\section{Kesimpulan}

Dari hasil sosialisasi ini dapat disimpulkan bahwa sosialisasi ini berhasil dapat dilihat dari analisis t-test yaitu adanya perbedaan antara pretest sebelum sosialisasi dan posttest setelah sosialisasi. Nilai pemahaman meningkat sekitar $17.4 \%$ dari rata-rata pretest tentang pemahaman awal investasi pasar uang dan saham. Ketertarikan mempelajari invenstasi saham banyak diikuti oleh mahasiswa sekaligus karyawan dikarenakan mereka sudah memiliki managemen keuangan masing-masing. Serta mayoritas peserta sekitar 74\% masih pernah belum mengikuti atau melakukan investasi di pasar uang dan modal sehingga hal ini dapat simpulkan bahwa investasi dengan cara ini masih ragu atau tidak diketahui oleh peserta. Dan juga minat berinvestasi dipasar saham masih tinggi secara keinginan sendiri, dikuti oleh adanya iklan dan influencer saham yang memperngaruhi orang-orang untuk menjadi investor, lalu ajakan atau ikut-ikutan teman. Sehingga seluruh peserta juga menginginkan pelatihan atau workshop secara mendalam mengenai pasar uang dan saham.

\section{Ucapan Terimakasih}

Dalam kegiatan pengabdian ini penulis mengucapkan terima kasih kepada Ketua STMIK Dharmapala Riau dan Ketua LPPM Dharmapala Riau yang sudah memberikan dukungan kepada kami secara finansial sehingga sosialisasi ini terlaksana. Tidak luput juga kami ucapkan kepada peserta yang sudah hadir dan berpartisipasi dalam mengikuti test awal dan akhir dari sosialisasi hingga selesai.

\section{Referensi}

Andriani, Dewi. (2021). Awas! Jangan Tergiur, Fenomena Munculnya Influencer Saham. Bisnis.com. Retrieved from https://finansial.bisnis.com/read/20210109/55/1340828/awas-jangan-tergiurfenomena-munculnya-influencer-saham

Anggraeni, Rina. (2021). Investor Pemula! Dengarkan Nih Saran BEI Soal Main Saham dari 'Uang Panas'. www.sindonews.com D Retrieved from https://ekbis.sindonews.com/read/306270/38/investor-pemula-dengarkan-nihsaran-bei-soal-main-saham-dari-uang-panas-1611028894

Bakhri, S. (2018). Minat Mahasiswa Dalam Investasi Di Pasar Modal. Al-Amwal: Jurnal Ekonomi Dan Perbankan Syari'ah. https://doi.org/10.24235/amwal.v10i1. 2846

Faisol, E. (2015). 1.600 Mahasiswa Semarang Investasi di Pasar Modal? Retrieved from https://m.tempo.co / /read/news/2015/04/15/090657820/1-600-mahasiswasemarang-investasidi-pasar-modal.

Hartono, Wira Jaya, Dkk, (2021). Students' Perceptions of Student Council Activity in New Normal Era at Junior High School. Atlantis Press: Proceedings of the 5th International Conference on Arts Language and Culture (ICALC 2020) https://doi.org/10.2991/assehr.k.210226.057

Intan, Novita dan Zuraya Nadia. (2021). Masa Pandemi, OJK Catat Pinjaman Online Capai Rp 146,25 T. Republika Indonesia. Retrieved from https://republika.co.id/berita/qmhr8k383/masa-pandemi-ojk-catat-pinjamanonline-capai-rp-14625-t 
Lidyana, Vadhia. (2021). Influencer Suka Pompom Saham? Simak Nih Peringatan BEI! detikFinance. Retrieved from https://finance.detik.com/bursa-dan-valas/d5351422/influencer-suka-pompom-saham-simak-nih-peringatan-bei

Martono, Nanang. (2010). Statistik Teori Sosial dan Aplikasi Program SPSS. Edisi Pertama. Jakarta: Gaya Media

Poluakan, M. V., Dikayuana, D., Wibowo, H., \& Raharjo, S. T. (2019). Potret Generasi Milenial pada Era Revolusi Industri 4.0. Focus: Jurnal Pekerjaan Sosial, 2(2), 187197.

Sandy, Kunthi Fahmar. (2021). Ini Kesalahan Investor Pemula, Yuk Hindari dengan Mengikuti Kelas Edukasi MNC Sekuritas. Idxchannel. Retrieved from https://www.idxchannel.com/market-news/ini-kesalahan-investor-pemula-yukhindari-dengan-mengikuti-kelas-edukasi-mnc-sekuritas.

Safitri, Kiki. (2021). Tips Investasi Saham untuk Investor Pemula. www.kompas.com Mengikuti Kelas Edukasi MNC Sekuritas. Idxchannel.com Retrieved from https://money.kompas.com/read/2021/03/25/144126926/simak-tips-investasisaham-untuk-investor-pemula 